\title{
Antioxidant Potential of Endemic Salvia absconditiflora
}

\author{
Hasan Akgül 1,a,", Nuh Korkmaz ${ }^{2, b}$, Alpaslan Dayangaçç,c, Mustafa Sevindik ${ }^{4, d}$ \\ ${ }^{1}$ Department of Biology, Faculty of Science, Akdeniz University, 07070 Antalya, Turkey \\ ${ }^{2}$ Department of Biology, Faculty of Science and Literature, Osmaniye Korkut Ata University, 80000 Osmaniye, Turkey \\ ${ }^{3}$ Department of Nutrition and Dietetics, Faculty of Health Sciences, Osmaniye Korkut Ata University, 80000 Osmaniye, Turkey \\ ${ }^{4}$ Department of Food Processing, Bahçe Vocational School, Osmaniye Korkut Ata University, 80000 Osmaniye, Turkey \\ *Corresponding author
}

\begin{tabular}{l|l}
\hline A R T I C L E I N F O & A B S T R A C T \\
\hline Research Article & $\begin{array}{l}\text { Medicinal plants are important natural materials used in the treatment of many diseases. In this } \\
\text { study, total antioxidant status (TAS), total oxidant status (TOS) and oxidative stress index (OSI) of } \\
\text { endemic Salvia absconditiflora Greuter \& Burdet were determined. Plant samples were collected } \\
\text { from Nigde and Erzincan (Turkey) provinces. Ethanol (EtOH) extracts of plant samples were } \\
\text { extracted. TAS, TOS and OSI values were determined using Rel Assay Diagnostics kits. As a result } \\
\text { of the studies, it has been determined that the samples of the plant collected from Nigde have higher } \\
\text { Accepted : 03/10/2020 } \\
\text { TAS, TOS and OSI values. As a result, it has been determined that } S \text {. absconditiflora can be used } \\
\text { as a potential antioxidant source due to high TAS values. }\end{array}$
\end{tabular}

Keywords:

Antioxidant

Oxidant

Medicinal plants

Salvia absconditiflora

Turkey

\section{Introduction}

Nature offers people many natural products of unique beauty. The demand for medicinal plants is increasing day by day. Plants from past to present have been used by people as fuel, clothing, shelter, food, and medicine. Different communities of the world such as China, Greek, Egypt, India, and Turk used plants for medicinal purposes and accessed very important information on this subject (Mohammed et al., 2018; Wang et al., 2018; Dent and Matoba, 2020). The use of medicinal plants in the treatment of diseases extends to the beginning of human life. In the early days, people used plants in the treatment of diseases by trial and error and observing animals. There are plant species specific to habitats in different parts of the world. These plant types are used locally in disease treatment (Chen et al., 2016; Karimi et al., 2017; Tasneem et al., 2019). Medicinal plants are referred to as plants that contain compounds that have drug effects. Many plant species have medicinal properties thanks to the bioactive compounds they produce. Different parts of medicinal plants such as roots, stems, leaves, flowers, fruits, or seeds contain drug-effective compounds at different levels. In this context, it is very important to determine the medicinal potential of plants (Shakya, 2016; Jamshidi-Kia et al., 2018; Roy et al., 2018).

The Salvia genus, which belongs to Lamiaceae family, is an annual, biennial, or perennial with about 900 species, that spreads as cosmopolitan in many parts of the world, and includes plants in herbaceous or bushy forms. Salvia absconditiflora Greuter \& Burdet is an endemic species. It spreads in rocky soils at altitudes between 700-2500 m. Flowering can be seen from May to August. It generally spreads on rocky limestone slopes, dry steppe, fallow fields, roadsides (Davis et al., 1982; Koysu et al., 2019). In our study, antioxidant potentials of $S$. absconditiflora collected from Nigde and Erzincan (Turkey) provinces were determined. 


\section{Materials and Methods}

Samples of $S$. absconditiflora were collected from Nigde and Erzincan (Turkey) provinces. The plant was identified using Flora of Turkey, volume 7 (Davis et al., 1982). After identification, the aerial parts of the plant were dried in a shady and ventilated environment. 30 gr of dry samples were weighed and extracted with $\mathrm{EtOH}$ at $50 \mathrm{0C}$ for approximately 6 hours (Gerhardt EV 14). The extracts obtained are concentrated with a rotary evaporator (Heidolph Laborota 4000 Rotary Evaporator).

Antioxidant, Oxidant and Oxidative Stress Index Tests The antioxidant and oxidant status of EtOH extracts of S. absconditiflora were determined using Rel Assay TAS and TOS kits. Trolox (TAS) and hydrogen peroxide (TOS) were used as calibrators (Erel, 2004; Erel, 2005). OSI (Arbitrary Unit $=$ AU) value was determined according to the following formula (Erel, 2005).

$$
\text { OSI }(\mathrm{AU})=\frac{\mathrm{TOS}, \mu \mathrm{mol} \mathrm{H}_{2} \mathrm{O}_{2} \text { equiv. } / \mathrm{L}}{\text { TAS, mmol Trolox equiv./L }} \times 100
$$

\section{Results and Discussion}

Antioxidant compounds are compounds that serve to suppress oxidant compounds. Living organisms produce reactive oxygen species as a result of environmental effects and metabolic activities. ROS produced at high levels can become harmful in living organisms. Antioxidant compounds suppress the negative effects of ROS. In cases where antioxidant compounds are insufficient, oxidative stress occurs. As a result of oxidative stress, Parkinson's, Alzheimer's, cancer, or cardiological disorders occur in humans. Supplementary antioxidants can be used to reduce the effects of oxidative stress (Eberhardt et al., 2000; Zhuo et al., 2011; Sevindik, 2020). In this context, it is very important to determine the potential of plants as a supplement antioxidant source. In this study, antioxidant, and oxidant potentials of $S$. absconditiflora collected from different regions were determined. In addition, the oxidative stress index, which indicates how much oxidant compounds are suppressed with antioxidant compounds, has been determined. The findings obtained are shown in table 1 .

Table 1. TAS, TOS and OSI values of S. absconditiflora

\begin{tabular}{l|ccc}
\hline Locality & TAS & TOS & OSI \\
\hline Nigde & $7.350 \pm 0.180$ & $8.501 \pm 0.267$ & $0.116 \pm 0.004$ \\
Erzincan & $6.979 \pm 0.100$ & $5.681 \pm 0.203$ & $0.081 \pm 0.003$ \\
\hline
\end{tabular}

Values are presented as mean \pm SD; Experiments were made in 5 parallels

TAS, TOS and OSI values of S. absconditiflora have not been previously determined in the literature. In our study, samples of $S$. absconditiflora collected from Nigde and Erzincan provinces were used as materials. As a result of the study, it was determined that TAS, TOS, and OSI values of samples collected from Nigde had higher than the samples collected from Erzincan. This difference between TAS values is thought to vary due to the potential amount of antioxidant compounds produced by the plant and environmental factors. Plants produce antioxidant effective secondary metabolites with different effects such as environmental factors. Herbal secondary metabolites may have considerable medical potential, even if they do not have nutritional properties (Dai and Mumper, 2010; Bouarab Chibane et al., 2019). In our study, it was determined that the samples of $S$. absconditiflora grown in Nigde have higher antioxidant potential than the samples grown in Erzincan. In addition, oxidant compounds produced with environmental effects in the plant were found to be higher in the samples grown in Nigde. Accordingly, it is seen that the plant samples collected from Nigde suppress oxidant compounds less than the samples collected from Erzincan. In TAS, TOS, and OSI studies conducted on plant species, TAS value of Salvia multicaulis was reported as 6.434, TOS value was 22.441, and OSI value was 0.349 (Pehlivan and Sevindik, 2018). TAS value of Mentha longifolia subsp. longifolia was reported as 3.628, TOS value was 4.046, and OSI value was 0.112 (Sevindik et al., 2017). TAS value of Calendula officinalis was reported as 5.55 (Verma et al., 2016). The TAS value of Thymbra spicata was reported as 8.399, TOS value was 6.530, and OSI value was 0.078 (Mohammed et al., 2020). TAS value of Gundelia tournefortii was reported as 6.831, TOS value was 3.712, and OSI value was 0.054 (Saraç et al., 2019). TAS value of Rumex crispus was reported as 6.758 , TOS value was 5.802, and OSI value was 0.086 (Durna Dastan et al., 2019). Compared to these studies, TAS values of $S$. absconditiflora both Nigde and Erzincan were higher than S. multicaulis, M. longifolia subsp. longifolia, C. officinalis, $G$. tournefortii, and $R$. crispus and lower than $T$. spicata. Compared to these studies, TAS values of $S$. absconditiflora both Nigde and Erzincan samples were determined by $S$. multicaulis, $M$. longifolia subsp. longifolia was higher than C. officinalis, G. tournefortii, and R. crispus, and lower than T. spicata. It is thought that this difference is due to the potential of plants to produce compounds with antioxidant properties. In this context, it has been determined that $S$. absconditiflora has significant antioxidant potential.

When TOS values were compared, it was determined that sample of $S$. absconditiflora collected from Nigde had lower values than $S$. multicaulis and higher than $M$. longifolia subsp. longifolia, T. spicata, G. tournefortii, and $R$. crispus. TOS value of sample collected from Erzincan was found to have lower than S. multicaulis, T. spicata, and $R$. crispus, and higher than M. longifolia subsp. longifolia and $G$. tournefortii. TOS values show all of the oxidant compounds produced by the plant with environmental effects (Mohammed et al., 2019). In this context, the variability of the habitat where $S$. absconditiflora grows also changes the levels of oxidant compounds. In addition, this difference in TOS values occurring between different plant species is thought to change due to the difference of plant species and the biotic-abiotic factors of the environment in which they grow.

The OSI value shows how much the antioxidant compounds in the plant suppress with oxidant compounds. As the OSI value increases, antioxidant system of the plant appears to work less (Mohammed et al., 2019). In our study, it is seen that samples of $S$. absconditiflora collected from Nigde suppress oxidant compounds better than $S$. multicaulis. The samples collected from Erzincan seem to 
suppress oxidant compounds better than $S$. multicaulis, $M$. longifolia subsp. longifolia, and $R$. crispus. As a result, it is seen that the antioxidant defense system of $S$. absconditiflora is sufficient in suppressing oxidant compounds.

\section{Conclusion}

In our study, antioxidant potential of $S$. absconditiflora was determined. As a result of the study, it was seen that antioxidant and oxidant values of the samples collected from different regions of the plant changed. In addition, it has been determined that $S$. absconditiflora has high antioxidant potential and can be used as a natural antioxidant source.

\section{Acknowledgment}

We thanks to Osmaniye Korkut Ata University, Central Research Laboratory for their support.

\section{References}

Al-Snafi AE, Talab TA, Majid WJ. 2019. Medicinal plants with central nervous activity-An overview (Part 1). IOSR Journal of pharmacy, 9(3): 52-102.

Bouarab Chibane L, Degraeve P, Ferhout H, Bouajila J, Oulahal N. 2019. Plant antimicrobial polyphenols as potential natural food preservatives. Journal of the Science of Food and Agriculture, 99(4): 1457-1474.

Chen SL, Yu H, Luo HM, Wu Q, Li CF, Steinmetz A. 2016. Conservation and sustainable use of medicinal plants: problems, progress, and prospects. Chinese medicine, 11(1): 37.

Dai J, Mumper RJ. 2010. Plant phenolics: extraction, analysis and their antioxidant and anticancer properties. Molecules, 15(10): 7313-7352.

Daştan SD, Durukan H, Demirbaş A, Dönmez E. 2019. Bioactivity and Therapeutic Properties of Evelik (Rumex crispus), A Naturally Growing and Edible Plant in Sivas Province. Turkish Journal of Agriculture-Food Science and Technology 7(2): 67-71.

Davis PH, Mill RR, Tan K. 1982. Flora of Turkey and the east Aegean 1slands. Edinburg Univsersty Press, 7, 433.

Dent M, Matoba N. 2020. Cancer biologics made in plants. Current opinion in biotechnology, 61: 82-88.

Eberhardt MV, Lee CY, Liu RH. 2000. Antioxidant activity of fresh apples. Nature, 405(6789): 903-904.

Erel O. 2004. A novel automated direct measurement method for total antioxidant capacity using a new generation, more stable ABTS radical cation. Clinical biochemistry, 37(4): 277- 285.

Erel O. 2005. A new automated colorimetric method for measuring total oxidant status. Clinical biochemistry, 38(12): 1103-1111.
Jamshidi-Kia F, Lorigooini Z, Amini-Khoei H. 2018. Medicinal plants: Past history and future perspective. Journal of herbmed pharmacology, 7(1): 1-7

Karimi M, Naghdi N, Naji-Haddadi S, Bahmani F. 2017. Medicinal plants used for kidney pain. Journal of Pharmaceutical Sciences and Research, 9(5): 542-546.

Koysu P, Genc N, Elmastas M, Aksit H, Erenler R. 2019. Isolation, identification of secondary metabolites from Salvia absconditiflora and evaluation of their antioxidative properties. Natural product research, 33(24): 3592-3595.

Mohammed FS, Akgul H, Sevindik M, Khaled BMT. 2018. Phenolic content and biological activities of Rhus coriaria var. zebaria. Fresenius Environmental Bulletin, 27(8): 56945702 .

Mohammed FS, Karakaş M, Akgül H, Sevindik M. 2019. Medicinal Properties of Allium calocephalum Collected from Gara Mountain (Iraq). Fresen Environ Bull, 28(10): 74197426.

Mohammed FS, Şabik AE, Sevindik E, Pehlivan M, Sevindik M. 2020. Determination of Antioxidant and Oxidant Potentials of Thymbra spicata Collected from Duhok-Iraq. Turkish Journal of Agriculture-Food Science and Technology, 8(5): 1171-1173.

Pehlivan M, Sevindik M. 2018. Antioxidant and antimicrobial activities of Salvia multicaulis. Turkish Journal of Agriculture-Food Science and Technology, 6(5): 628-631.

Roy A, Jauhari N, Bharadvaja N. 2018. Medicinal Plants as. Anticancer Plants: Natural Products and Biotechnological Implements, 2(2): 109.

Saraç H, Demirbaş A, Daştan SD, Ataş M, Çevik Ö, Eruygur N. 2019. Evaluation of Nutrients and Biological Activities of Kenger (Gundellia tournefortii L.) Seeds Cultivated in Sivas Province. Turkish Journal of Agriculture-Food Science and Technology, 7(2): 52-58.

Sevindik M, Akgul H, Pehlivan M, Selamoglu Z. 2017. Determination of therapeutic potential of Mentha longifolia ssp. longifolia. Fresen Environ Bull, 26: 4757-4763.

Shakya AK. 2016. Medicinal plants: future source of new drugs. International Journal of Herbal Medicine, 4(4): 59-64.

Tasneem S, Liu B, Li B, Choudhary MI, Wang W. 2019. Molecular pharmacology of inflammation: Medicinal plants as anti-inflammatory agents. Pharmacological research, 139: 126-140.

Verma PK, Raina R, Sultana M, Singh M, Kumar P. 2016. Total antioxidant and oxidant status of plasma and renal tissue of cisplatin-induced nephrotoxic rats: protection by floral extracts of Calendula officinalis Linn. Renal failure, 38(1): 142-150.

Wang TY, Li Q, Bi KS. 2018. Bioactive flavonoids in medicinal plants: Structure, activity and biological fate. Asian Journal of Pharmaceutical Sciences, 13(1): 12-23.

Zhuo W, Liao L, Xu T, Wu W, Yang S, Tan J. 2011. Mesenchymal stem cells ameliorate ischemia-reperfusioninduced renal dysfunction by improving the antioxidant/oxidant balance in the ischemic kidney. Urologia internationalis, 86(2): 191-196. 